Review Article

\title{
Environmental Characteristics of Polybrominated Diphenyl Ethers in Marine System, with Emphasis on Marine Organisms and Sediments
}

\author{
Ying Zhang, ${ }^{1,2}$ Weiliang Wang, ${ }^{1,2}$ Jinming Song, ${ }^{3}$ Zongming Ren, ${ }^{1,2}$ Huamao Yuan, ${ }^{3}$ \\ Huijun Yan, ${ }^{2}$ Jinpeng Zhang, ${ }^{2}$ Zhen Pei, ${ }^{2}$ and Zhipeng $\mathrm{He}^{4}$ \\ ${ }^{1}$ Institute of Environment and Ecology, Shandong Normal University, Jinan 250014, China \\ ${ }^{2}$ College of Geography and Environment, Shandong Normal University, Jinan 250014, China \\ ${ }^{3}$ Institute of Oceanology, Chinese Academy of Sciences, Qingdao 266071, China \\ ${ }^{4}$ Fishery Design Institute of Shandong Province, Jinan 250014, China \\ Correspondence should be addressed to Jinming Song; jmsong@qdio.ac.cn and Zongming Ren; zmren@sdnu.edu.cn
}

Received 20 June 2016; Accepted 18 September 2016

Academic Editor: Francesco Dondero

Copyright ( 2016 Ying Zhang et al. This is an open access article distributed under the Creative Commons Attribution License, which permits unrestricted use, distribution, and reproduction in any medium, provided the original work is properly cited.

\begin{abstract}
Polybrominated diphenyl ethers (PBDEs), due to their widespread usage as flame retardants and their lipophilicity and persistence, have become ubiquitous in the environment. It is urgent to understand the environmental characteristics of PBDEs in marine system, but they have attracted little attention. We summarize the available data and analyze the regional distributions, controlling factors, and congener patterns of PBDEs in marine and associated environmental matrixes worldwide. Based on meta-analysis, after separating the estuarial sites from the marine sites, ignoring the extraordinary sample sites such as those located just near the point source, the PBDE concentration levels are still in the same order of magnitude from global scale. Despite Principal Component Analysis, the congener patterns of sediments are predominant with the heavy brominated congeners (BDE-209 contributing over $75 \%$ to the total load) while the biota abound with the light ones (BDE-47, BDE-99, and BDE-100 taking about $80 \%$ ). The ratio between BDE-99 and BDE-100 for the lower trophic-level species often turns to be greater than 1, while for those higher species the ratio may be below 1 , and some species feed mainly on the crustaceans and zooplankton seems to have a higher ratio value. The data of the PBDEs in marine system are currently limited; thus, data gaps are identified as well.
\end{abstract}

\section{Introduction}

Polybrominated diphenyl ethers (PBDEs) have been produced and applied extensively as additive brominated flame retardants (BFRs) in various consumer products, such as plastics, textiles, and electronic equipment, in recent decades [1-3], as they are not chemically bond to materials and can be easily released into environment during production, use, disposal, and recycling process. PBDEs are highly hydrophobic and bioaccumulative [4-6] and have the propensity to enter the gas phase at ambient conditions and undergo longrange atmospheric transport $[7,8]$. They have been found to have a ubiquitous environmental distribution and have been measured at remote sites, like the Arctic, where they had never been used $[9,10]$ and are ubiquitous in the sediments [11], soil [12], air [13], and divers biotic species [14]. PBDEs exposure has become a worldwide pollution problem. These properties led to the inclusion of the penta- and octatechnical mixtures in Annex A (elimination) of the convention (SC$4 / 14$ and SC-4/18) at the meeting of the conference of parties (COP) in May 2009 [15]. It seems to be the morning twilight to solve the environmental problem of PBDEs. However, recent publications report that, overall, legacy PBDEs are still identified at higher concentrations than emerging non-PBDE BFRs in Europe [14].

Scientists are devoted to flesh out the status of PBDE contaminations in environment. PBDEs have been the focus of numerous studies and reviews for over decades [14], 
including the regional distributions [16-18], exposures [19, 20], toxicities [21], and time trends [22, 23], but seldom of them have been conducted concerning the environmental characteristic in marine system. Ocean is the major sink of these pollutants, via (i) direct deposition from the atmosphere, (ii) runoff from land, (iii) direct discharge from industry or wastewater treatment $[2,24-26]$. Ocean plays an important role in the fate of PBDEs via gravitational sinking of particulates into sediments and their biotransformation via biometabolism process. It is urgent to determine their distributions in marine environment, based not only on the absence of any previous data, but also on the complexity of their environmental fate and effects, coupling with bioaccumulation potential, environmental recalcitrance, and potential human and wildlife toxicities.

The object of this review is to reanalyze the published data to portray the current state of knowledge about the distributions, contents of PBDEs in marine environment worldwide, where sediments and biota are specially emphasized on. The controlling factors on the distributions of PBDEs in matrixes are also discussed here. Furthermore, congener patterns in marine and associated environmental matrixes are discussed in detail. The data for PBDEs in marine system are currently limited; thus, research recommendations and data gaps are identified and discussed as well.

\section{Data Treatment}

PBDEs are presented as mixtures of congeners, and thus the set of congeners reported in the various papers were not consistent. It is somewhat difficult to evaluate the relative degree of PBDE contaminations across various studies. As a compromise of the divergence comes from congeners chosen, several aspects were taken as considerations. We were inclined to choose (i) the major components in the three commercial products (Penta-, Octa-, and Decamixtures) (such as BDE-47, BDE-99, BDE-100, and BDE-153 in Pentamixtures and BDE-153, BDE-183, BDE-197, and BDE207 in Octamixtures, and BDE-209 in Decamixtures [27]); (ii) those frequently reported (such as BDE-15, BDE-17, BDE28, BDE-47, BDE-66, BDE-85, BDE-99, BDE-100, BDE-138, BDE-153, BDE-154, BDE-183, and BDE-209); (iii) excluding those playing a minor role to the total load or even generally under the determine limit ones (such as BDE-15, BDE-17, BDE-66, BDE-85, and BDE-138). Therefore, only eight congeners, BDE-28, BDE-47, BDE-99, BDE-100, BDE-153, BDE154, BDE-183, and BDE-209 are selected for investigation due to the above considerations. The total PBDE concentrations have been normalized to the sum of the eight congeners (hereafter referred to as $\sum_{8}$ PBDEs, except when stated otherwise), to exclude the variances of the congener numbers detected.

The units are made consistent in the same matrix. For example, ng/g dry weight for sediments and ng/g lipid weight for marine organisms. ng/g wet weight was converted to lipidadjusted concentrations, using given lipid concentrations or estimating from other published researches (as described below). Unit of the atmosphere samples is consisted on pg $\mathrm{m}^{-3}$.
As the data from various studies cannot be assumed to be normally distributed, in some studies one or two of the sample locations may have been easily disturbed by occasional point source inputs [28], and median value is chosen to evaluate the polluted levels of PBDEs rather than average.

In our review, the median was chosen to evaluate the polluted levels of PBDEs rather than average, because the data from various study cannot be assumed to be normally distributed; in some parts of the study one or two of the sample locations may have been easily disturbed by occasional point source inputs.

In most of the study the concentrations of congeners in some samples were not available because of being lower than detection level. Several authors treated these missing values as zero or half of the detection limit. Besides these methods, compound ratios are used in the sum to assess the concentration of these congeners. A compound ratio (CR) is the ratio between two or several compounds, as defined in

$$
\mathrm{CR}=\frac{a_{1}}{a_{1}+a_{2}} .
$$

In the formula, $a_{1}$ and $a_{2}$ are the concentration of compounds 1 and 2 in a sample. When using compound ratios, missing values do not affect all variables, and their affecting ratios are defined as missing. If the missing values are up to $50 \%$, the method is not to be used anymore.

Principal Component Analysis performed by SPSS (version 22.0) ORIGIN (9.0) is used to compare the congener patterns of PBDEs in the sediment, biological, atmosphere samples, and three commercial mixtures.

\section{Marine Environmental Levels}

PBDEs released from various sources can be transported into marine system via riverine inputs and atmospheric deposition. PBDEs have high binding affinity to particles and lipids and tendency to accumulate in sediment $[26,29]$ and biota [30]. Since the hydrophobicity nature, PBDEs have very low water solubility [2], and only a little portion of the PBDEs exist in the water phase. Due to the lower concentrations and technical difficulty in measurement, to our knowledge, few papers have been published related with sea water [31, 32]. Here, main focuses were set on the sediment and biota matrixes.

3.1. Sediment. Sediment is an important sink of anthropogenic pollutants and has large impact on their distributions and transport in aquatic environment [33]. We examined most of the available published works and recalculated the published data to understand the regional distributions of PBDEs in marine sediments. Although the published data are still far more enough to describe the worldwide contamination situation of PBDEs in marine environment, unless we have no other choice as noticed in the manuscript or Table 1 , most of the interesting data referring to other aquatic environment such river $[11,34]$ or lake $[35,36]$ are not included in this section, and even some of the papers reported that the data on marine sediment are not included either, if 


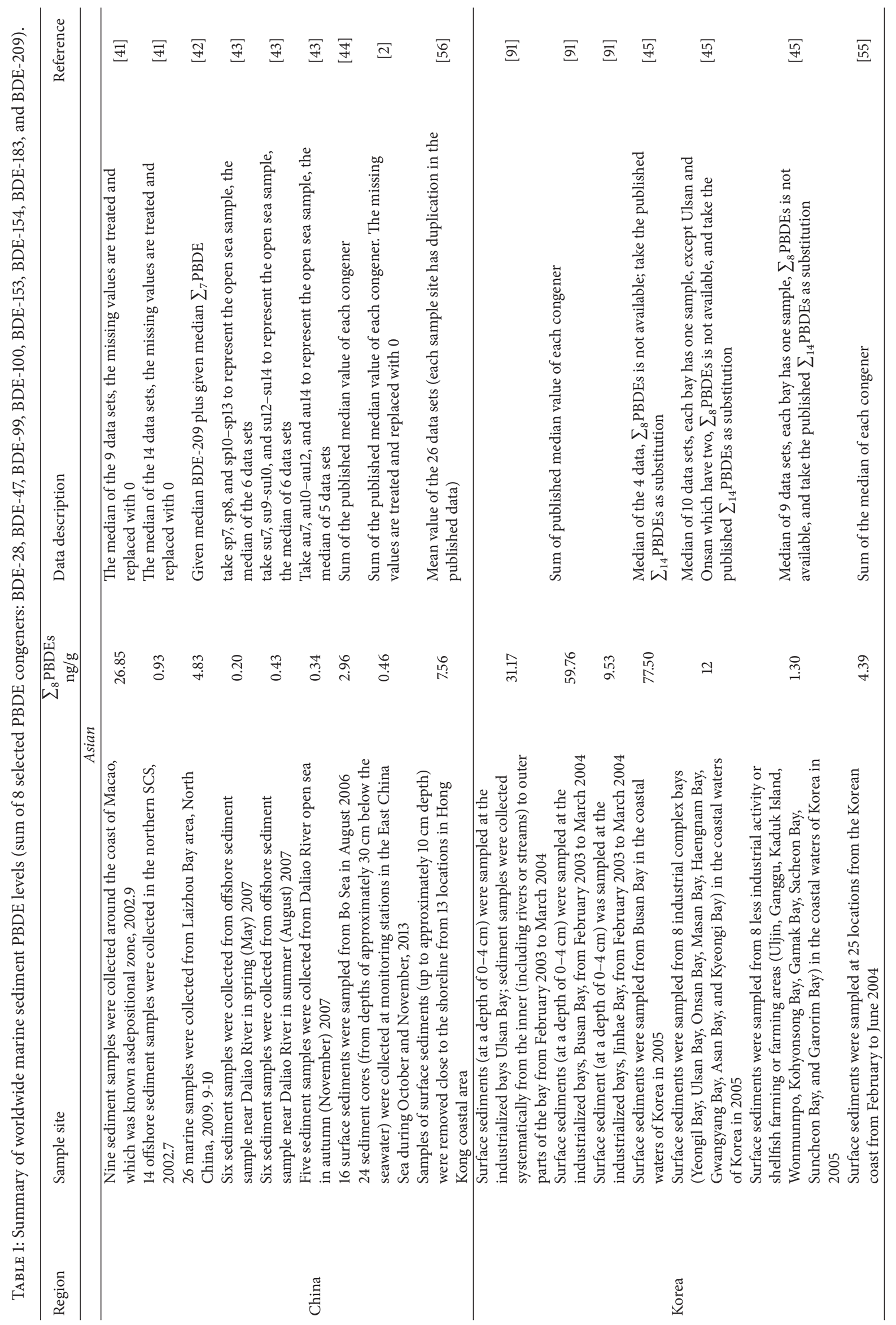




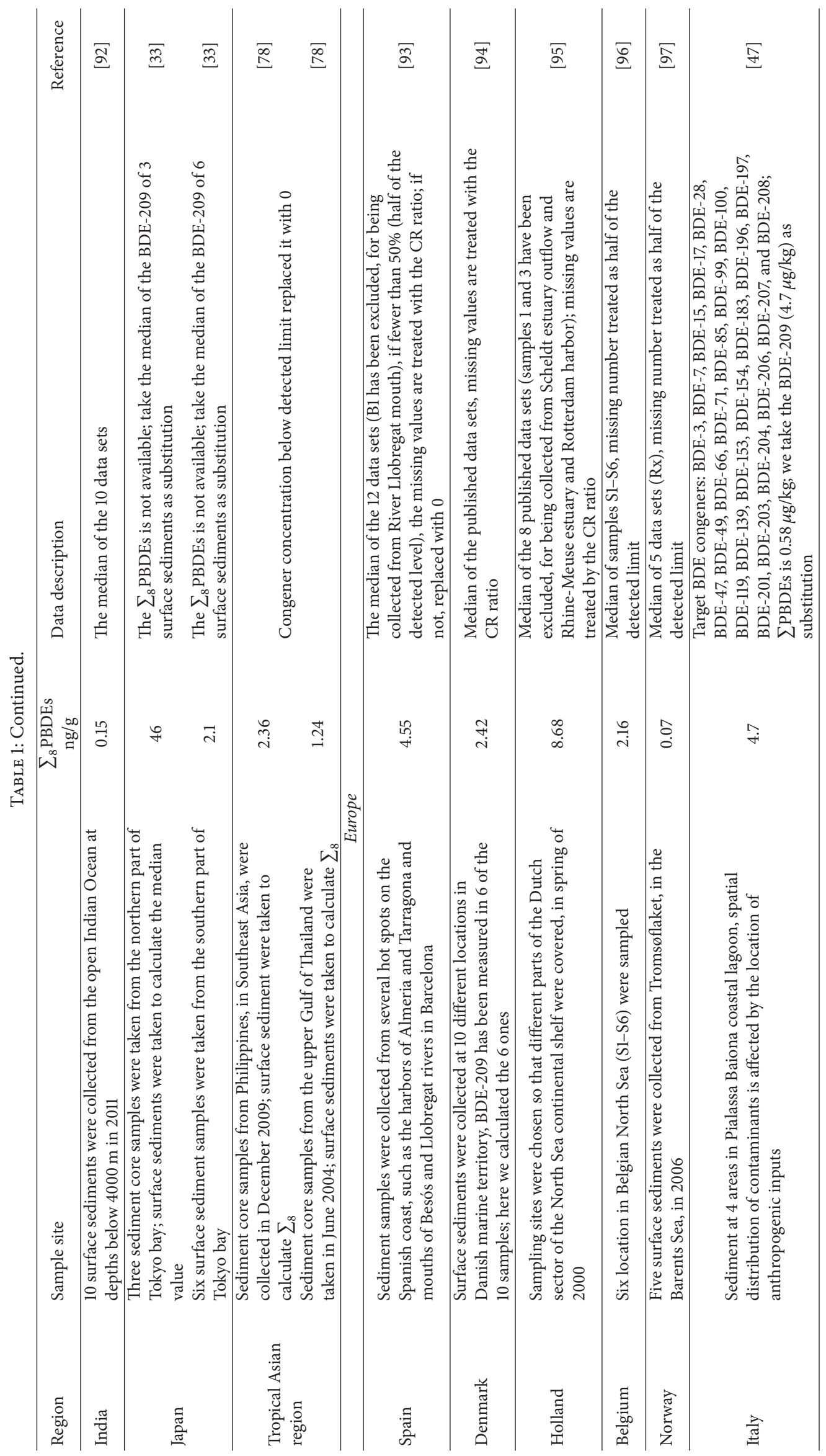




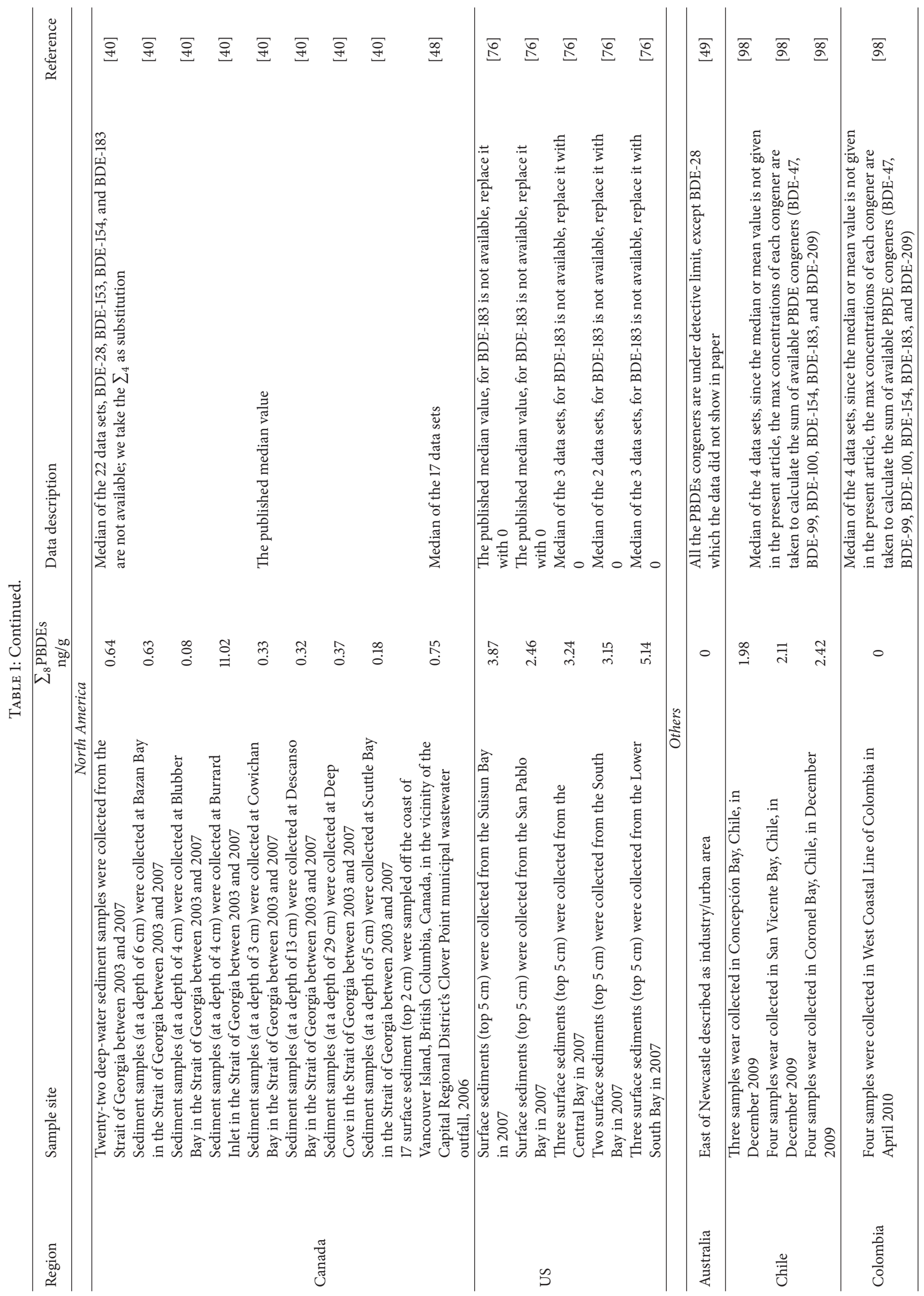


the BDE-209 (mostly the dominant congener in sediment) was not available for us [37].

As shown in Table 1, pollution level is still comparable within the data collected worldwide. When we reanalyzed the published data, separated the estuary sites from the marine sites, and ignore the extraordinary sample sites such as those located just near the source input point, the concentration levels from the different marine areas may be at the same order of magnitude. Even in the United States, a lot of the scientists declared that the contamination of PBDEs was the most serious one $[38,39]$. It is said that nearly half of the total amounts of PBDEs of the world were used in America in 2001. Taking look at the research carried in San Francisco Bay sediments, the median values of $\sum_{8}$ PBDEs in each sample area (Suisun Bay, San Pablo Bay, San Pablo Bay, and South Bay) are about 2-6 ng/g. The median value of 22 samples representing the deep-water area of Strait of Georgia, $\sum_{8}$ PBDEs, is below $1 \mathrm{ng} / \mathrm{g}$ [40]. It is still comparable to the European samples (shown in Table 1), which seem to be the less polluted regions in the world according to the previous comments. In China, recently, not only the South China Sea but also the northern or eastern part of China Sea, such as BO Sea or East China Sea, has been investigated. Data indicate that, in the samples collected from offshore sediment of northern South China Sea, $\sum_{8}$ PBDEs is $0.93 \mathrm{ng} / \mathrm{g}$ [41] and from East China Sea it is below $1 \mathrm{ng} / \mathrm{g}$ [2], and all of median values of each published paper concerning northern part of China, for example, Laizhou Bay, Bo Sea, do not exceed $5 \mathrm{ng} / \mathrm{g}$ [4244]. In terms of Korea, in surface sediments sampled from 8 less industrial activity or Shellfish farming or farming areas (Uljin, Ganggu, Kaduk Island, Wonmunnpo, Kohyonsong Bay, Gamak Bay, Sacheon Bay, Suncheon Bay, and Garorim Bay) the median value of the published $\sum_{14}$ PBDEs [45] is $1.3 \mathrm{ng} / \mathrm{g}$. In Tokyo Bay, PBDE concentrations decreased from north (near Tokyo municipal areas) to south. Separating the impacted sites, $\sum_{8}$ PBDEs is $2.1 \mathrm{ng} / \mathrm{g}$ [33].

It seems that as long as the investigation sites located at a certain distance from the source pollution point, the PBDE concentrations would drop a lot, and finally from region to region they would not vary a lot. However, the pollution status from different countries is still not the same. It is hard to conduct a global monitoring program to precisely assess the pollution situation, and thus we take a look at the pollution sites; the values from diverse regions are quite different, some of the highest reported BDE-209 concentrations in sediments are $7340 \mathrm{ng} / \mathrm{g}$ in the Dongjiang River near a heavily industrialized area in southern China [41], and concentrations of BDE-209 in the Osaka Bay are (7.8-350 ng/dry wt) [46]. Conversely, in sediment at four areas in Pialassa Baiona coastal lagoon, spatial distribution of contaminants is affected by the location of anthropogenic inputs, the median of the sum of PBDEs is less than $6 \mathrm{ng} / \mathrm{g}$ [47], 17 surface sediments (top $2 \mathrm{~cm}$ ) were sampled off the coast of Vancouver Island, British Columbia, Canada, and in the vicinity of the Capital Regional District's Clover Point municipal wastewater outfall, 2006, $\sum_{8}$ PBDEs is $0.75 \mathrm{ng} / \mathrm{g}$ [48]; Furthermore, in sample from east of Newcastle, Australian, described as Industry/urban area, the PBDEs still cannot be detected [49].
High levels of PBDEs were detected in sediments from river estuaries but drop quickly along with the distance from seashore. That is because, comparing with polluted river and some of the waste water receiving lake, owning to the distant from the input sources, marine sediment can receive much less pollutants. Besides, one of the major routes for pollutants going into ocean is riverine input. The high affinity of PBDEs to particulate and precipitate into the sediment may result in sedimentation and burial of PBDEs to the river sediment and significantly reduce the amount of transportable PBDEs to marine system [50].

3.2. Biota. When comparing the data of sorts of biological samples, it is not wise to draw any conclusion just by looking at tissue levels without regard for the species variation. Concentrations of PBDEs in food webs from the Baltic Sea and the northern Atlantic Sea indicated that the detected $\sum_{8}$ PBDEs had a great difference between perch $(17.13 \mathrm{ng} / \mathrm{g}$ lipid weight) and pike (111.94 ng/g lipid weight) [51]. According to published reports, PBDE levels in marine mammals may be generally one or more orders of magnitude higher than those in the invertebrates and fish collected from the corresponding sampling sites [52], as shown in Figure 1. Hence, in order to make a comparable data description, the discussion is limited to bivalves, which are the most commonly used bioindicator species $[53,54]$. The median of lipid-normalized $\sum_{8}$ PBDEs levels in mussels collected from 25 coastal locations in Korea was detected at concentration of $142.74 \mathrm{ng} / \mathrm{g}$ lipid weight [55] (original data quoted based on the wet weight, recalculated by present authors). PBDE concentrations measured in these samples, excluding BDE209, were lower than those reported from other countries, whereas BDE-209 concentrations were comparable to or higher than those reported from other countries. In their study, the predominant BDE congener in bivalves was DecaBDE, which accounted for $>60 \%$ of the total PBDEs [55]. Green-lipped mussels were used to investigate the concentrations of PBDEs in Hong Kong's marine environment. $\sum_{8}$ PBDEs ranged from 909.1 to $5545.4 \mathrm{ng} / \mathrm{g}$ lipid weight of mussel tissue, with a median high up to $2734.5 \mathrm{ng} / \mathrm{g}$ lipid weight [56]. Original data are quoted based on the dry weight, recalculated by present author using the lipid content, $1.1 \%$ derived from the data published by Phillips [53]. It was 23 orders of magnitude higher than that observed in France which was only $8.75 \mathrm{ng} / \mathrm{g}$ lipid weight in the mussels (in the absence of BDE-209). According to early study, mussel was collected from New Bedford Harbor, MA, USA, every alternate year from 1991 to 2005. The sum of the existing $\mathrm{BDE}$ congener $(28,47,99$, and $100, \mathrm{BDE}-209$ is not the target analysis conger) $\sum \mathrm{PBDE}$ concentrations in mussel tissues was in the ranges of 64 to 241 (mean, 135), 128 to 681 (mean, 295), and 128 to 364 (mean, 256) ng/g lipid weight at reference site, upper harbor, and lower harbor, respectively [37].

\section{Controlling Factors}

4.1. Sediment. The distribution patterns of PBDEs in sediments are complex and varied from area to area, as the distributions are controlled by several potential factors, including 


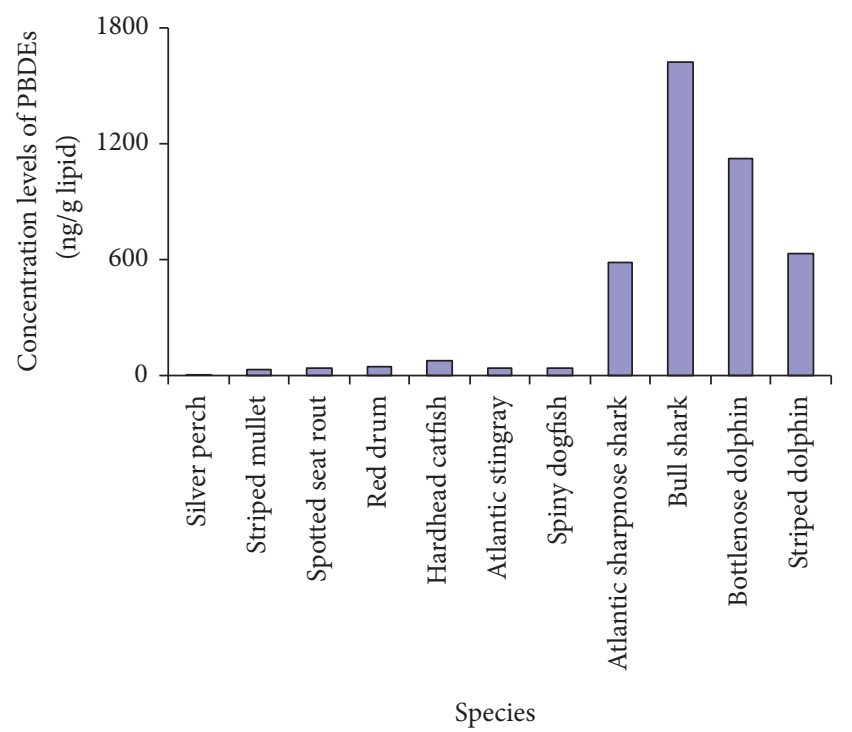

Figure 1: Mean value of lipid-normalized concentrations of $\sum_{8}$ PBDEs in different species from Florida coastal waters [52].

the source composition, environmental degradation, and sedimentary environment. Grain size and organic matter content are the main characteristics of sediments and the principal factors that control the sorption of hydrophobic organic contaminants [57-59].

PBDEs can be readily adsorbed on the particulate matters due to their high hydrophobicities [60]. Grain size can reflect the hydromechanic nature of deposition; it is very important to differentiate the sedimentary environment. It appears that the distribution of PBDEs pattern resembles to that of grain size as described in Jiaozhou Bay [61]. The covariation phenomenon was also demonstrated in Moon and his colleagues' work; grain size was described as factors that control the sorption of hydrophobic organic contaminants [55]. It is still hold true for the study in East China Sea. It presented a broad similar pattern between low-percentage sandy sediments and the concentrations of PBDEs [62], while the rule is not suitable for the South China Sea [41].

Because of their hydrophobicity, organic pollutants are frequently adsorbed to particles with high organic carbon contents in the environment. Some studies have reported that total organic carbon (TOC) is a principal factor that determines the adsorption of organic compounds, such as organic chlorine pesticides (OCPs) [63], polybrominated biphenyls (PCBs) [64], and chlorinated paraffin (CP) [65] in sediments from some regions. Several researchers also found a positive correlation between the distribution of PBDEs and organic carbon in sediment of a river estuary $[4,43]$. However, poor correlations have also been observed between TOC and PBDEs in other areas [2, 41, 62, 66, 67].

The inconsistent distribution patterns may come from the following reasons. They may be due to the fact that researchers found that sediment organic matter differs in chemical composition and function among different size fractions. The coarse-size fractions may contain considerable inputs of coal and black carbon particles, leading to high
OC concentrations. On the other hand, the higher OC concentrations of the finer-size fractions are often due to their large specific surface area and their high sorption for natural organic matter [58].

The congener-specific partitioning of halogenated contaminants onto sediments of differing sizes may be another potential reason. Generally, because of the greater organic content and surface area of smaller sediment fractions (i.e., colloidal and particulate organic carbon, organic detritus, silts, and clays), heavier congeners have a greater affinity for these sediments than smaller congeners based on equilibrium partitioning theory [68]. Rayner and his colleagues came up with a hypothesis that congener-specific partitioning occurs among sediment grains of different sizes and that the smaller grains are enriched in the contribution of higher brominated congeners such as BDEs-99 and BDEs-100 (only lightly brominated congeners from mono- through hexabrominated were discussed) [68]. Other studies have shown that heavier PBDE congeners are the most correlated ones with sediment grain size thus emphasizing the strong particle affinity of these compounds [69].

Besides, the possible reasons why the correlation between PBDEs and grain size or TOC is week may also be influenced by the intensive land-based inputs [70, 71], disturbed by occasional point source inputs [66], and degradation and reapportionment of PBDEs in water column during resuspension and long-range transport processes [60], or it can be concluded that it resulted from the combined effect of water dynamic, transport, mixing, and depositional mechanisms associated with PBDEs [41].

4.2. Biota. PBDE levels in biota can be influenced by many factors; besides environmental exposure, the deviations in species, sex, age, exposure duration, temperature, and latitude are all potential factors influencing bioaccumulation of PBDEs in marine organisms.

Apart from the PBDE concentrations in environmental medium, species distinction may be the dominated factor of all. Nine species of marine fish, including teleost fish, sharks, and stingrays, and two species of marine mammals (dolphins) collected from Florida coastal waters were analyzed for PBDEs. As shown in Figure 1, mean concentrations of PBDEs in different species fluctuated greatly from each other. The $\sum_{8}$ PBDEs levels measured in muscle tissues of teleost fish ranged from $6.5 \mathrm{ng} / \mathrm{g}$ lipid weight (in silver perch) to $77.4 \mathrm{ng} / \mathrm{g}$ lipid weight (in hardhead catfish). The levels may be about more than 10-fold higher in muscle of sharks ranging from $37.1 \mathrm{ng} / \mathrm{g}$ lipid weight (in spiny dogfish) to $1623.2 \mathrm{ng} / \mathrm{g}$ lipid weight (in bull sharks). In the blubber of marine mammals, high on the food chain such as bottlenose dolphins and striped dolphins, even the mean concentrations (1120.8 and $632.7 \mathrm{ng} / \mathrm{g}$ lipid weight, resp.) might be comparable to the maximum value in bull sharks. Concentrations of PBDEs in dolphins and sharks were 1-2 orders of magnitude greater than those in lower trophic-level fish species [52]. The same conclusion can be drawn by investigating the levels of individual PBDE congeners in various species from North Sea, such as invertebrate species (whelk, starfish, and hermit crab), the gadoid fish species (whiting and cod), and the 
marine mammal species (harbor seal and harbor porpoise). In the invertebrates, the $\sum_{8}$ PBDEs was found only to be ranging from 23.2 to $57.7 \mathrm{ng} / \mathrm{g}$ lipid weight. However, the $\sum$ PBDEs levels in harbor porpoise liver and blubber were up to 1762 and $1555 \mathrm{ng} / \mathrm{g}$ lipid weight, respectively, which were generally one or more orders of magnitude higher than in the invertebrates [72].

The results obtained showed a positive correlation between trophic-level and PBDE concentrations [51, 72], which clearly points toward biomagnification potential of these chemicals [30]. Previous studies pointed out that the major biomagnification step in the food chain occurs from fish to marine mammals [72]. However, no clear trends could be discovered to suggest any biomagnification from benthic organisms to fish [73]. It can be partially interpreted by the differences in feeding behavior, nutritional status [74], and metabolic capacity. In addition, some researchers stated that body size would play an important role in the biomagnification processes. The size among the lower trophic-level species, such as fish and invertebrates, did not change a lot, whereas it could change a lot between the marine mammals and fish. The ratio of the total surface area of an animal to its size got smaller when size increased. The surface area of the gill membrane to total animal volume also had influence. Both factors resulted in enhanced partition of hydrophobic chemicals between the water and organisms due to body sizes of the organisms and lower elimination rates in larger animals $[72,75]$.

Even the same species may have different body burden levels of PBDEs. Previous studies had shown lower PBDE levels to occur in adult female marine mammals than in males, reanalysis of the data published by [76]; the median of adult female harbor seal $(709.25 \mathrm{ng} / \mathrm{g}$ lipid) is lower than the male (1098.4 ng/g lipid). The reason was that they can dispose their contaminants during spawning by incorporating large amounts of fat and persistent pollutants in the roe $[29,73]$, and as a consequence pollutant transferred to their offspring during gestation and lactation [74].

The sampling time and metabolic capacity can influence the accumulation processes as well. The organisms suffering from the long-term exposure to the PBDEs may have higher body burden levels than that collected immediately after exposure, for the accumulation processes. Besides, the metabolic capacity played an important role in the processes, since some of the congeners may be metabolized and expelled as dejection.

\section{Congener Distributions in Matrixes}

The congener distribution patterns for the commercial mixtures (Penta-, Octa-, and Decamixtures) and for the samples of sorts of matrixes from Asia, Europe, and America are analyzed by Principal Component Analysis based on the proportion of eight individual PBDE congeners relative to the $\sum_{8}$ PBDEs concentrations. The samples were selected representing or associating with marine environment, such as sediments from estuary, coast, or open sea and biotic species (invertebrates, fish, or marine mammals) along with airborne PBDEs, which is one of the most important paths by which
PBDEs transport into the ocean. The Principal Component Analysis plot revealed compositional similarity and differences both between and within environmental matrixes and commercial mixtures. The component plot of component 1 versus component 2 is shown in Figure 2. The first two principal components explained $88.95 \%$ of the total variability of the data set. As shown in Figure 2, the data points nominated as “*.\#n" indicated "*" matrixes, "\#” region, and " $n$ " sample numbers. The abbreviations indicated the character of these samples: for matrixes, $\mathrm{S}$ is sediments; $\mathrm{BI}$ is invertebrates; $\mathrm{BF}$ is fish; $\mathrm{BM}$ is marine mammals; $\mathrm{A}$ is atmosphere; and for region, $\mathrm{C}$ is China; $\mathrm{K}$ is Korea; $\mathrm{J}$ is Japan; $\mathrm{U}$ is United States; E is Europe; SEA is Southeast Asia (detailed data description is listed in Table S1 in Supplementary Material available online at http://dx.doi.org/10.1155/2016/1317232). There is clear segregation of three-group cluster around the commercial mixtures. Group A has a similar compositional pattern to that of the Decamixtures, with relative predominant congener of 209. In this group, most of the data represent sediment samples, airborne particles, and some biological samples. Group B includes most of the biological samples which are similar to the Pentamixtures (Tetra- and Penta-BDEs are prevalent congeners) on the composition. The congener patterns will be discussed in detail in later section in this paper with the sequence of sample matrixes.

It is interesting to notice that some of the samples from China have a similar compositional pattern to that of the Octamixtures, as shown in Figure 2, uniquely gathering in group C.

The samples collected from China, unlike those collected from other countries, are similar to the Octamixtures and have a relative high proportion of BDE-183 to the total load of $\sum_{8}$ PBDEs (not only the sediment sample, some of the human sample also showed the same distribute pattern; see our previous publication [77]). This unexpected phenomenon can be interpreted by the fact that China is the major port of electronic-waste (e-waste). BDE-183 can be an indicator congener of Octamixtures, which are primary used in the resin or polymer applied to electronic industry $[78,79]$. The use of Octamixtures has been banned in all applications in the European Union Market since August 2004 (Brominated Science and Environmental Forum web site), and the Great Lake Chemical Corporation (USA) had agreed to phase out the production of the chemicals by the end of 2004 [80]. However, the electronic applications produced in America and Europe years before 2004, incorporated with these toxic chemicals, may come to the end of their "life span" and be discarded as e-waste years after ban-time. Instead of being recycled locally, these e-wastes carrying the toxic Octamixtures have been exported to developing countries, such as China. Therefore, some of the samples collected from China may have high proportions of BDE-183, similar to Octamixtures in congener patterns, uniquely gathering in the group $\mathrm{C}$.

5.1. Sediment. As shown in Figure 2, on the top left corner of the figure, most of the sediment samples cluster together (group A), which are similar in compositional pattern to the Decamixtures. That is because the moderately and heavily substituted BDE congeners predominate over 


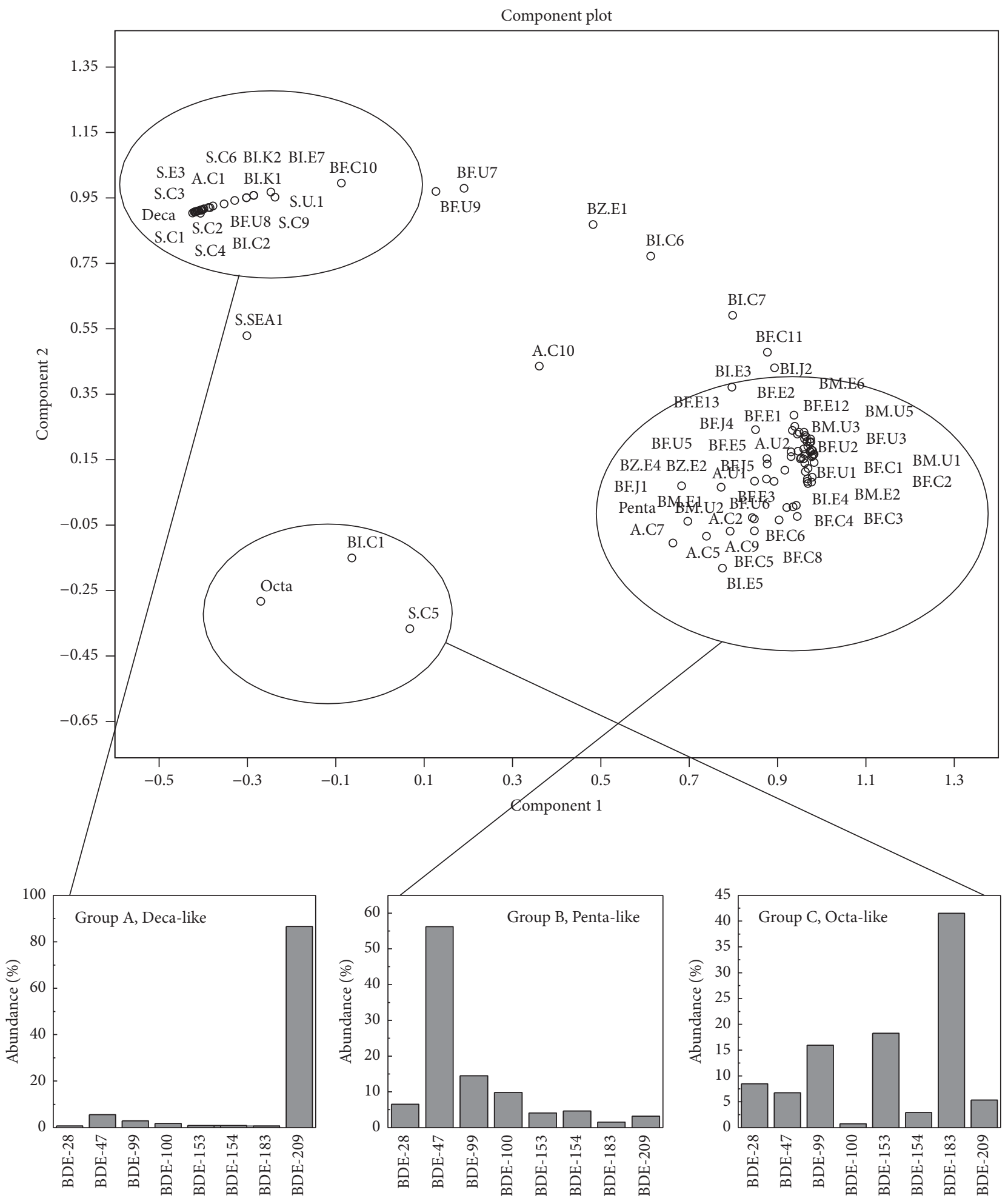

FIGURE 2: Plot of first two factors of Principal Component Analysis of PBDE congener patterns for matrixes (sediments, biotic species, and atmosphere) from Asia, America, and Europe.

the less brominated congeners in the sediments, especially BDE-209, which is the major congener detected in the two Decamixtures (Saytex 102E and Bromkal 82-0DE) accounting for $96.8 \%$ and $91.6 \%$ for the total load, respectively [27], in the meantime, dominating the congener patterns in the sediments representing over $85 \%$ of the $\sum_{8}$ PBDEs in each study, except the samples from Hong Kong [56]. The levels of BDE-209 are 1-3 orders of magnitude higher than the 
sum of the concentrations of Tri- to Hepta-BDEs in some studies. There are reasons accounting for the abundance of BDE-209 in the profiles. PBDEs were reported to be introduced into marine system through wet and dry deposition [81]. Studies indicated that the percentage of contaminant adsorbed to particles in both air and wet deposition increased with bromination [81]. Studies showed that compositions of PBDEs at urban and suburban sites were similar, in which BDE-209 was the dominated congener [82], with an annual average contribution to $\sum$ PBDEs of $64 \pm 23 \%$ in an across-China study [83] or $40-99 \%$ in south China. In these samples BDE-209 was the predominant one over the 11 congeners investigated, accounting for $40-99 \%$ for the total PBDE concentrations in the atmosphere samples, except for some irregular site as stated [28]. Along with the determination from deposition, the physical-chemical properties of the individual congeners play an important role as well. According to the octanol-water partition coefficient, it is expected that the heavier brominated congener (such as BDE-209) has high affinity to particulate and precipitate into the sediment [7]. Furthermore, BDE-47 and BDE-99 and some other lighter congeners are easier to be taken up by organism while not being restrict into the sediment. All of the reasons above may lead to the predomination of BDE-209 in the congener patterns in sediment.

5.2. Biota. PBDE congener patterns of most biota from all over the world seem to resemble to each other, irrespective of levels, fish species, and sampling sites. Most of the data points cluster together with the Pentamixtures. BDE-47 and BDE-99 are the main components of the Pentamixtures, including DE-71 (which has a composition of $38.2 \%$ and 48.6\%) and Bromkal 70-5DE (which has a composition of $42.8 \%$ and $44.8 \%$ ) [27]. The percentage of BDE-209, which is the main component of Decamixtures, is much lower than that of BDE-47 and BDE-99 in biological samples. The general order of decreasing contribution to the total load is BDE-47 > BDE-99, BDE-100 > BDE-153, BDE-154. BDE-47, BDE-99, and BDE-100 make up about $80 \%$ on average of the $\sum_{8}$ PBDEs. It is clear that in biological samples the congeners are dominated by the light brominated ones and are obviously different from those in sediment and airborne particle samples, which are dominated by BDE209 [84]. The distinction comes from the different bioavailability between those congeners. Bioaccumulation of PBDEs with six or more bromine atoms seems to be correlated negatively with the degree of bromination [72]. The reason may be that the relatively high molecular weight (644-959 Dalton) or molecular size leads to inefficient dietary uptake [29].

As shown in Figure 2, not all biological samples cluster around the Pentamixtures. The congener patterns of some biotic species are much more similar to those of Decamixtures than others, because the samples contain more BDE209 than other species. BDE-209 has been considered to be nonbioavailable, because its large molecular size may impede its passage across tissue membranes in biota [29]. However, some studies have demonstrated that organisms were able to take up BDE-209. In laboratory, experiments were carried out to confirm that the BDE-209 could be taken up by carp, and uptake of BDE-209 was estimated to be $3.2 \%$ [85]. But the accumulation efficiency is extremely low. It has been proved that BDE-209 can be metabolized by juvenile carp, since no net accumulation of BDE-209 was observed throughout the experiment despite an exposure concentration of $940 \mathrm{ng} / \mathrm{day} / \mathrm{fish}$ [85]. The same metabolic capability can be observed in rainbow trout. Dietary uptake and effects of BDE-209 were studied in rainbow trout. Fish were fed Deca-BDE for 49 days and then on control diet for 71 days to study depuration. After depuration, BDE-209 concentrations declined. Generally, as a result of biotransformation processes, BDE-209 has a short half-life in organisms $[72,73]$. No matter whether the BDE-209 can be taken up by organisms or not, the rapid metabolism and elimination of this congener may sequentially result in its absence in biota as well. To our knowledge, no integrated study has figured out the relationship between metabolic capacity and taxonomic group. The absence and presence of BDE-209 can be attributed to the metabolic differences between species and the depuration time somehow. The irregular points (BZ.E1, BI.E7, BF.U7, BF.U8, and BF.U9) include the zooplanktons, roach [29], and sharks (spiny dogfish, Atlantic sharpnose shark, and bull shark) [52]. It seems that these species, compared with other marine organisms, can accumulate the BDE-209 effectively and have a relative long residue time.

Besides the reasons mentioned above, another significant reason should be taken to account for the elevated proportion of BDE-209. In Figure 2, the data point (BI.K1) of bivalves collected from Korean coastal belongs to group A, with a high percentage of BDE-209 of the total load. This is due to the approach of the sample preparation. In their study, the mussels analyzed were not depurated, and the whole soft tissues were pooled and homogenized [55]; therefore, the presence of particles in the gut may contribute to the high BDE-209 concentration measured. Filter-feeding mussels ingested the contaminants adsorbed on small particles [55]. Booij et al. [86] suggested that BDE-209 levels measured in mussels were dominated by the concentrations found in ingested particles in the gut. This also can explain the data point BI.C2, representing for the mussel from China.

In the present study, different ratios between BDE-99 and BDE-100 were calculated in different species (as shown in Figure 3). The statement made earlier by Christensen et al. has shown that the mean ratio between BDE-99 and BDE-100 in marine environment locations which were not excessively polluted was equal to $30: 70$. Actually, however, according to our analytical data, it is evident that the ratio is much like the species-depended. The ratio varied in species even though the samples were collected from the same region. In addition to the exposure ambient, molecular size, and bioavailability, the metabolic differences between the species would be an important reason accounting for the variance. Voorspoels et al. have observed that the ratio found for shrimp $(20: 80)$ was very similar to the ratio for the Bromkal mixtures and virtually identical to the ratio found in Western Scheldt Estuary sediments [73]. This result was consistent with the measured ratio in shrimp and the sediments of the 


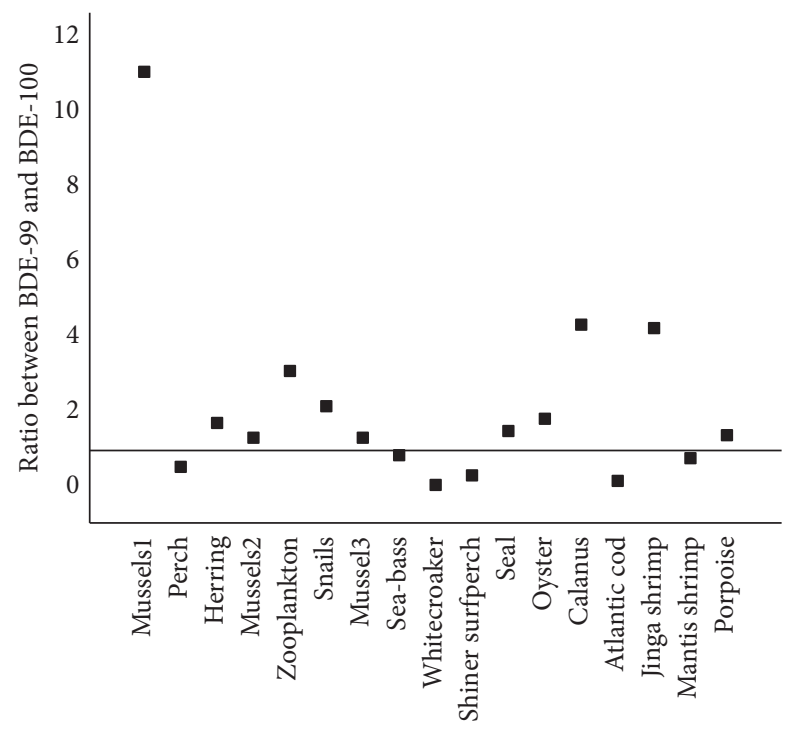

FIgurE 3: The ratio between BDE-99 and BDE-100 for different species. The lower trophic-level species, like mussels and shrimp (lake of metabolic capability), often turns to be greater than 1, while for those higher species, like fish or marine mammals (elimination of BDE-99), the ratio may be below 1 . It is worthy to mention that some species feed mainly on the crustaceans and zooplankton seems to have a higher ratio value, as mentioned in the manuscript (data are collected from references [29, 44, 51, 55, 56, 72, 76, 87, 99-101]).

Pearl River estuary [87]. Shrimp simply reflected the Bromkal and sediment constitution patterns for these congeners, suggesting that these compounds were readily bioavailable, but shrimp clearly lacked metabolic capability [87]. Hites reported that the selective environmental elimination of BDE-99 had been observed in some biota [88]. The marine organisms seemed to increase their metabolic capabilities when they climb the evolutionary ladder [73]. The ratio between BDE-99 and BDE-100 for the lower trophic-level species, like mussels, snail, shrimp, and Calanus, and so forth (lake of metabolic capability), often turns to be greater than 1 , while for those higher species, like fish or marine mammals (elimination of BDE-99), the ratio may be below 1 . It is worthy to mention that some species feed mainly on the crustaceans and zooplankton seems to have a higher ratio value, such as herring [51, 52, 72], striped mullet [52], or stingray [52] (as shown in Figure 3).

5.3. Atmosphere. As mentioned above, atmosphere transportation is one of the major routes for PBDEs to transport, redistribute, and finally deposit into marine system. To estimate the load of PBDEs to marine system, the atmospheric compositional pattern should be figured out to quantify and predict their environmental fate and transport.

As shown in Figure 2, some of the atmospheric samples (A.C1, A.C3) belong to group A, which might be similar to the Decamixtures in composition. On the contrary, the samples (A.C2, A.U1, and A.U2) belong to group B which might have a similar compositional pattern to that of the Pentamixtures. That is due to the atmospheric PBDE partitions between the vapor and particulate phases. On the basis of the KOA values [26], it can be predicted that the lighter congeners (e.g., BDE-47, BDE-99, and BDE-100) will exist almost entirely in the gas phase, whereas the heavier brominated congeners (BDE-153, BDE-154, and BDE-183) will be predominantly associated with particles [26]. BDE-209, according to its physical-chemical properties (e.g., a log subcooled liquid vapor pressure, $V_{p}$ of -8.68 , and an octanol-water partition coefficient, $K_{\mathrm{ow}}$, of 9.97), is expected to be partitioned entirely to the particle phase in both air and rain [81].

Taking the gas-particle partitioning of PBDEs into consideration, the compositional pattern for particulate phase is similar to that of sediments (group A), in which the relative abundance of BDE-209 is extremely high as well. This can be served as a potent evidence for the fact that wet or dry deposition is one of the major sources of the PBDEs in marine sediments, whereas the gas phase has a similar congener pattern to that of biological samples (group B), and the lighter congeners contribute more than heavier ones to the total load.

Atmosphere samples were collected from four sites in the city of Guangzhou, a typical urban center in south China to determine the gas-particle partitioning of 11 PBDE congeners. The average relative abundances of PBDEs have shown that the Tetra- to Hepta-BDEs were present in both the gas and particulate phases. The Tri-BDE (BDE-28) was present almost exclusively in the gas phase (96-98\%) [28]; therefore, the data point of gas phase sample (A.C2) belonged to group $B$, whereas the Deca-BDE (BDE-209) was found only in the particulate phase [28], resulting in clustering together with group A. In some studies the atmosphere samples contain both the particle and gas phases. It becomes difficult to predict whether it will have a Deca-like profile or Pentaprofile, since it depends on which phase will be the dominant one.

Along with the gaseous or particulate phases of samples, the sample location may significantly influence the composition profile of atmosphere sample. In samples collected from urban or suburban sites in China, the dominating conger is BDE-209, and background/rural air sites, however, are BDE47 followed by BDE- 99 . These differences can be explained as BDE-209 is easy to bound to particles and hence less subject to migrate with air mass movement to the background/rural sites in comparison to other less brominated PBDEs [83]. In both urban and background/rural sites, the ratio for BDE-209 to the total PBDE in Chinese ambient air was greater than that in air of the United States [89], while the ratios for BDE-47 and BDE-99 in Chinese air were smaller than those in the US air, which is possibly due to the larger usage of Pentamixtures in the United States [89] and Decamixtures in China [83].

\section{Recommendations and Data Gaps}

Marine system plays an important role in the environment [24]. However, studies on PBDEs in marine system are patchy and fragmented. Most of the sampling sites have been conducted in the bay or near coastal area, which could be strongly affected by municipal and industrial wastewaters containing high levels of anthropogenic pollutants. Some of sample locations even are situated near point sources such 
as harbors or wastewater treatment plants, where concentrations in various environmental matrixes are predicatively to be relatively high [40]. For a complete understanding of the distribution of PBDEs in marine system, the investigation should be expanded geographically. Such background locations and open sea area should also be included.

The congeners determined varied from study to study, which has been an impediment for comparing the conclusion across various studies. The different polluted level may come from how many and which congeners are determined, rather than actual polluted status. BDE-209 is of special importance because it is suspected to be the predominant congener in the sediments and it may account for over $85 \%$ in the samples. Owing to the unmeasurement of BDE-209, the pollution level would be underestimated. The US Environmental Protection Agency has made a list of 16 "priority pollutant polycyclic aromatic hydrocarbons (PAHs)" that are indicative for monitoring PAH contaminations. There is an urgent need to make a list to guide the researchers in determining congeners to whom priority investigation are warranted.

To quantify and predict their environmental behaviors of PBDEs in the marine system, there is a clear need for more systematic environmental monitoring to understand how and where these chemicals are being released into the environment and what is happening to them once they enter the environment. But the researches focused their attention ex parte on the sediments and biota [7]. Extra emphasis should be placed upon the water column, suspended particles, microlayer, and pore-water and properties in environment such as redox conditions and salinity or some other geoenvironmental parameter worth for future studies, to understand what are the fluxes of these chemicals into marine system, what is happening to them once they enter the environment, and what fate and transport processes that are involved in their environmental movement.

Some of previous studies paid attention to the debromination process of these chemicals in the lab; modeled or field study of PBDEs in real situation is urgently needed. It is a major knowledge gap to understand what debromination process these chemicals undergo in the practical situation. Can these chemicals be hydrolyzed, photolyzed, reductively decomposed in the water, particle, and sediment, or metabolized by marine organisms? And if yes, what are the resultant products? Do these degradation products turn to be more deleterious or harmless to the organisms? And is there any appropriate way to degrade or assimilate the increasing PBDEs in marine system? There are still a lot of questions waiting to be resolved.

The Penta-BDE and Octa-BDE commercial mixtures have been banned in the European Union (EU) in 2004 and were included in the Stockholm Convention of Persistent Organic Pollutants (POPs). In addition, Deca-BDE has also been proposed for listing under the convention [15]. Despite the ending of the production and use, large quantities of articles containing PBDEs are still in use as well as in the recycling and end-of-life flows [90]. Therefore, some trend study, such as taking sediment core as information carrier or using material flows approach, should be done to understand or predict the existing and potential risk.

\section{Competing Interests}

All authors declared that they have no proprietary, financial, professional, or other personal interest of any nature or kind in any products cited in the paper.

\section{Authors' Contributions}

Ying Zhang and Weiliang Wang made equal contribution to the paper.

\section{Acknowledgments}

This study was financially supported in part by the Natural Science Foundation of China (nos. 41606125, 40821004, 21107135, and 40906056), the National Key Project for Basic Research of China (no. 2007CB407305), and the Jinan Highlevel Talent Plan (2013041).

\section{References}

[1] W. A. Stubbings and S. Harrad, "Extent and mechanisms of brominated flame retardant emissions from waste soft furnishings and fabrics: a critical review," Environment International, vol. 71, pp. 164-175, 2014.

[2] L. Liu, H. Li, Z. Wang, R. Liu, Y. Zhang, and K. Lin, "Insights into spatially and temporally co-occurring polybrominated diphenyl ethers in sediments of the East China Sea," Chemosphere, vol. 123, pp. 55-63, 2015.

[3] M. R. Earnshaw, K. C. Jones, and A. J. Sweetman, "A first European scale multimedia fate modelling of BDE-209 from 1970 to 2020," Environment International, vol. 74, pp. 71-81, 2015.

[4] H. J. Lee, S. An, and G. B. Kim, "Background level and composition of polybrominated diphenyl ethers (PBDEs) in creek and subtidal sediments in a rural area of Korea," Science of the Total Environment, vol. 470-471, pp. 1479-1484, 2014.

[5] D. Deng, H. Chen, and N. F. Y. Tam, “Temporal and spatial contamination of polybrominated diphenyl ethers (PBDEs) in wastewater treatment plants in Hong Kong," Science of the Total Environment, vol. 502, pp. 133-142, 2015.

[6] C. Nelson, K. Drouillard, K. Cheng, J. Elliott, and N. Ismail, "Accumulation of PBDEs in an urban river otter population and an unusual finding of BDE-209," Chemosphere, vol. 118, no. 1, pp. 322-328, 2015.

[7] C. A. de Wit, "An overview of brominated flame retardants in the environment," Chemosphere, vol. 46, no. 5, pp. 583-624, 2002.

[8] N. G. Dodder, K. A. Maruya, G. G. Lauenstein, J. Ramirez, K. J. Ritter, and K. C. Schiff, "Distribution and sources of polybrominated diphenyl ethers in the Southern California Bight," Environmental Toxicology and Chemistry, vol. 31, no. 10, pp. 2239-2245, 2012.

[9] K. Vorkamp and F. F. Rigét, "A review of new and currentuse contaminants in the Arctic environment: evidence of longrange transport and indications of bioaccumulation," Chemosphere, vol. 111, pp. 379-395, 2014.

[10] A. Rotander, B. van Bavel, A. Polder et al., "Polybrominated diphenyl ethers (PBDEs) in marine mammals from Arctic and North Atlantic regions, 1986-2009," Environment International, vol. 40, no. 1, pp. 102-109, 2012.

[11] T. Wang, S. Li, C. Zhang, and Y. Li, "Quantities, sources and adsorption of polybrominated diphenyl ethers in components 
of surficial sediments collected in Songhua River (Jilin City), China," Chemosphere, vol. 119, pp. 1208-1216, 2015.

[12] Y. Sun, G.-L. Yuan, J. Li, J.-C. Li, and G.-H. Wang, "Polybrominated diphenyl ethers in surface soils near the Changwengluozha Glacier of Central Tibetan Plateau, China," Science of the Total Environment, vol. 511, pp. 399-406, 2015.

[13] P. Luo, H.-G. Ni, L.-J. Bao, S.-M. Li, and E. Y. Zeng, "Size distribution of airborne particle-bound polybrominated diphenyl ethers and its implications for dry and wet deposition," Environmental Science and Technology, vol. 48, no. 23, pp. 13793-13799, 2014.

[14] C. Munschy, N. Olivier, B. Veyrand, and P. Marchand, "Occurrence of legacy and emerging halogenated organic contaminants in marine shellfish along French coasts," Chemosphere, vol. 118, no. 1, pp. 329-335, 2015.

[15] Stockholm Convention, 2016, http://chm.pops.int/Convention/ ThePOPs/TheNewPOPs/tabid/2511/Default.aspx.

[16] G. T. Yogui and J. L. Sericano, "Polybrominated diphenyl ether flame retardants in the U.S. marine environment: a review," Environment International, vol. 35, no. 3, pp. 655-666, 2009.

[17] G. Yu, Q. Bu, Z. Cao et al., "Brominated flame retardants (BFRs): a review on environmental contamination in China," Chemosphere, vol. 150, pp. 479-490, 2016.

[18] S. A. Mackintosh, J. S. Wallace, M. S. Gross et al., "Review on the occurrence and profiles of polybrominated diphenyl ethers in the Philippines," Environment International, vol. 85, pp. 314326, 2015.

[19] L. Bramwell, S. V. Glinianaia, J. Rankin et al., "Associations between human exposure to polybrominated diphenyl ether flame retardants via diet and indoor dust, and internal dose: a systematic review," Environment International, vol. 92-93, pp. 680-694, 2016.

[20] H. Fromme, G. Becher, B. Hilger, and W. Völkel, "Brominated flame retardants-exposure and risk assessment for the general population," International Journal of Hygiene and Environmental Health, vol. 219, no. 1, pp. 1-23, 2016.

[21] L. Yu, Z. Han, and C. Liu, "A review on the effects of PBDEs on thyroid and reproduction systems in fish," General and Comparative Endocrinology, vol. 219, pp. 64-73, 2015.

[22] A. Miller, J. E. Elliott, K. H. Elliott et al., "Brominated flame retardant trends in aquatic birds from the Salish Sea region of the west coast of North America, including a mini-review of recent trends in marine and estuarine birds," Science of the Total Environment, vol. 502, pp. 60-69, 2015.

[23] R. J. Law, A. Covaci, S. Harrad et al., "Levels and trends of PBDEs and HBCDs in the global environment: status at the end of 2012," Environment International, vol. 65, pp. 147-158, 2014.

[24] Y.-F. Guan, J.-Z. Wang, H.-G. Ni, X.-J. Luo, B.-X. Mai, and E. Y. Zeng, "Riverine inputs of polybrominated diphenyl ethers from the Pearl River Delta (China) to the coastal ocean," Environmental Science \& Technology, vol. 41, no. 17, pp. 6007-6013, 2007.

[25] M.-Y. Zou, Y. Ran, J. Gong, B.-X. Mai, and E. Y. Zeng, "Polybrominated diphenyl ethers in watershed soils of the Pearl River Delta, China: occurrence, inventory, and fate," Environmental Science \& Technology, vol. 41, no. 24, pp. 8262-8267, 2007.

[26] B. Gevao, M. U. Beg, A. N. Al-Ghadban, A. Al-Omair, M. Helaleh, and J. Zafar, "Spatial distribution of polybrominated diphenyl ethers in coastal marine sediments receiving industrial and municipal effluents in Kuwait," Chemosphere, vol. 62, no. 7, pp. 1078-1086, 2006.
[27] G. M. LaA, R. C. Hale, and E. Harvey, "Detailed polybrominated diphenyl ether (PBDE) congener composition of the widely used penta-, octa-, and deca-PBDE technical flame-retardant mixtures," Environmental Science \& Technology, vol. 40, no. 20, pp. 6247-6254, 2006.

[28] L.-G. Chen, B.-X. Mai, X.-H. Bi et al., "Concentration levels, compositional profiles, and gas-particle partitioning of polybrominated diphenyl ethers in the atmosphere of an urban city in South China," Environmental Science and Technology, vol. 40, no. 4, pp. 1190-1196, 2006.

[29] S. Burreau, Y. Zebühr, D. Broman, and R. Ishaq, "Biomagnification of polychlorinated biphenyls (PCBs) and polybrominated diphenyl ethers (PBDEs) studied in pike (Esox lucius), perch (Perca fluviatilis) and roach (Rutilus rutilus) from the Baltic Sea," Chemosphere, vol. 55, no. 7, pp. 1043-1052, 2004.

[30] V. Bragigand, C. Amiard-Triquet, E. Parlier, P. Boury, P. Marchand, and M. El Hourch, "Influence of biological and ecological factors on the bioaccumulation of polybrominated diphenyl ethers in aquatic food webs from French estuaries," Science of the Total Environment, vol. 368, no. 2-3, pp. 615-626, 2006.

[31] Y.-F. Guan, O. S. S. Sojinu, S.-M. Li, and E. Y. Zeng, "Fate of polybrominated diphenyl ethers in the environment of the Pearl River Estuary, South China," Environmental Pollution, vol. 157, no. 7, pp. 2166-2172, 2009.

[32] H.-G. Ni, F.-H. Lu, X.-L. Luo et al., "Assessment of sampling designs to measure riverine fluxes from the Pearl River Delta, China to the South China Sea," Environmental Monitoring and Assessment, vol. 143, no. 1-3, pp. 291-301, 2008.

[33] N. H. Minh, T. Isobe, D. Ueno et al., "Spatial distribution and vertical profile of polybrominated diphenyl ethers and hexabromocyclododecanes in sediment core from Tokyo Bay, Japan," Environmental Pollution, vol. 148, no. 2, pp. 409-417, 2007.

[34] V. Verhaert, A. Covaci, S. Bouillon et al., "Baseline levels and trophic transfer of persistent organic pollutants in sediments and biota from the Congo River Basin (DR Congo)," Environment International, vol. 59, pp. 290-302, 2013.

[35] G. Su, D. Saunders, Y. Yu et al., "Occurrence of additive brominated flame retardants in aquatic organisms from Tai Lake and Yangtze River in Eastern China, 2009-2012," Chemosphere, vol. 114, pp. 340-346, 2014.

[36] G. Poma, C. Roscioli, and L. Guzzella, "PBDE, HBCD, and novel brominated flame retardant contamination in sediments from Lake Maggiore (Northern Italy)," Environmental Monitoring and Assessment, vol. 186, no. 11, pp. 7683-7692, 2014.

[37] B. Subedi, S. Yun, S. Jayaraman, B. J. Bergen, and K. Kannan, "Retrospective monitoring of persistent organic pollutants, including PCBs, PBDEs, and polycyclic musks in blue mussels (Mytilus edulis) and sediments from New Bedford Harbor, Massachusetts, USA: 1991-2005," Environmental Monitoring and Assessment, vol. 186, no. 8, pp. 5273-5284, 2014.

[38] M. J. Parascandola, PBDEs in Breast Milk-Levels Higher in United States than in Europe, Environmental Health Perspectives, 2003.

[39] A. Sjödin, D. G. Patterson Jr., and Å. Bergman, "A review on human exposure to brominated flame retardants-particularly polybrominated diphenyl ethers," Environment International, vol. 29, no. 6, pp. 829-839, 2003.

[40] P. B. C. Grant, S. C. Johannessen, R. W. Macdonald et al., "Environmental fractionation of PCBs and PBDEs during particle transport as recorded by sediments in coastal waters," 
Environmental Toxicology and Chemistry, vol. 30, no. 7, pp. 15221532, 2011.

[41] B. X. Mai, S. J. Chen, X. J. Luo et al., "Distribution of polybrominated diphenyl ethers in sediments of the Pearl River Delta and adjacent South China Sea," Environmental Science \& Technology, vol. 39, no. 10, pp. 3521-3527, 2005.

[42] X. Pan, J. Tang, J. Li, G. Zhong, Y. Chen, and G. Zhang, "Polybrominated diphenyl ethers (PBDEs) in the riverine and marine sediments of the Laizhou Bay area, North China," Journal of Environmental Monitoring, vol. 13, no. 4, pp. 886-893, 2011.

[43] X. Zhao, H. Zhang, Y. Ni et al., "Polybrominated diphenyl ethers in sediments of the Daliao River Estuary, China: levels, distribution and their influencing factors," Chemosphere, vol. 82, no. 9, pp. 1262-1267, 2011.

[44] Z. Wang, X. Ma, Z. Lin, G. Na, and Z. Yao, "Congener specific distributions of polybrominated diphenyl ethers (PBDEs) in sediment and mussel (Mytilus edulis) of the Bo Sea, China," Chemosphere, vol. 74, no. 7, pp. 896-901, 2009.

[45] K. Ramu, T. Isobe, S. Takahashi et al., "Spatial distribution of polybrominated diphenyl ethers and hexabromocyclododecanes in sediments from coastal waters of Korea," Chemosphere, vol. 79, no. 7, pp. 713-719, 2010.

[46] S. Ohta, T. Nakao, H. Nishimura, T. Okumura, O. Aozasa, and H. Miyata, "Contamination levels of PBDEs, TBBPA, PCDDs/ DFs and PXDDs/DFs in the environment of Japan," Organohalogen Compounds, no. 57, pp. 57-60, 2002.

[47] R. Guerra, A. Pasteris, S.-H. Lee, N.-J. Park, and G. Ok, "Spatial patterns of metals, PCDDs/Fs, PCBs, PBDEs and chemical status of sediments from a coastal lagoon (Pialassa Baiona, NW Adriatic, Italy)," Marine Pollution Bulletin, vol. 89, no. 1-2, pp. 407-416, 2014.

[48] A. M. H. DeBruyn, L. M. Meloche, and C. J. Lowe, "Patterns of bioaccumulation of polybrominated diphenyl ether and polychlorinated biphenyl congeners in marine mussels," Environmental Science \& Technology, vol. 43, no. 10, pp. 3700-3704, 2009.

[49] L.-M. L. Toms, M. Mortimer, R. K. Symons, O. Paepke, and J. F. Mueller, "Polybrominated diphenyl ethers (PBDEs) in sediment by salinity and land-use type from Australia," Environment International, vol. 34, no. 1, pp. 58-66, 2008.

[50] H. Wei, A. C. Aziz-Schwanbeck, Y. Zou et al., "Polybromodiphenyl ethers and decabromodiphenyl ethane in aquatic sediments from Southern and Eastern Arkansas, United States," Environmental Science \& Technology, vol. 46, no. 15, pp. 80178024, 2012.

[51] S. Burreau, Y. Zebühr, D. Broman, and R. Ishaq, "Biomagnification of PBDEs and PCBs in food webs from the Baltic Sea and the northern Atlantic Ocean," Science of the Total Environment, vol. 366, no. 2-3, pp. 659-672, 2006.

[52] B. Johnson-Restrepo, K. Kannan, R. Addink, and D. H. Adams, "Polybrominated diphenyl ethers and polychlorinated biphenyls in a marine foodweb of coastal Florida," Environmental Science \& Technology, vol. 39, no. 21, pp. 8243-8250, 2005.

[53] D. J. H. Phillips, "Organochlorines and trace metals in greenlipped mussels Perna viridis from Hong Kong waters: a test of indicator ability," Marine Ecology Progress Series, vol. 21, pp. 251258, 1985 .

[54] A. Calisi, "Evaluation of pollution effects in marine organisms: 'old' and 'new generation' biomarkers," in Coastal Ecosystems: Experiences and Recommendations for Environmental Monitoring Programs, M. T. Sebastià, Ed., pp. 143-192, Nova Science, New York, NY, USA, 2015.
[55] H.-B. Moon, K. Kannan, S.-J. Lee, and M. Choi, "Polybrominated diphenyl ethers (PBDEs) in sediment and bivalves from Korean coastal waters," Chemosphere, vol. 66, no. 2, pp. 243-251, 2007.

[56] Y. Liu, G. J. Zheng, H. Yu et al., "Polybrominated diphenyl ethers (PBDEs) in sediments and mussel tissues from Hong Kong marine waters," Marine Pollution Bulletin, vol. 50, no. 11, pp. 1173-1184, 2005.

[57] X. Pan, J. Tang, J. Li, Z. Guo, and G. Zhang, "Levels and distributions of PBDEs and PCBs in sediments of the Bohai Sea, North China," Journal of Environmental Monitoring, vol. 12, no. 6, pp. 1234-1241, 2010.

[58] X. Zhao, B. Zheng, Y. Qin, L. Jiao, and L. Zhang, "Grain size effect on PBDE and PCB concentrations in sediments from the intertidal zone of Bohai Bay, China," Chemosphere, vol. 81, no. 8, pp. 1022-1026, 2010.

[59] B. Zheng, X. Zhao, L. Liu et al., "Effects of hydrodynamics on the distribution of trace persistent organic pollutants and macrobenthic communities in Bohai Bay," Chemosphere, vol. 84, no. 3, pp. 336-341, 2011.

[60] Y. Li, T. Lin, Y. Chen, L. Hu, Z. Guo, and G. Zhang, "Polybrominated diphenyl ethers (PBDEs) in sediments of the coastal East China Sea: occurrence, distribution and mass inventory," Environmental Pollution, vol. 171, pp. 155-161, 2012.

[61] J. Pan, Y.-L. Yang, Q. Xu, D.-Z. Chen, and D.-L. Xi, "PCBs, PCNs and PBDEs in sediments and mussels from Qingdao coastal sea in the frame of current circulations and influence of sewage sludge," Chemosphere, vol. 66, no. 10, pp. 1971-1982, 2007.

[62] H. Li, J. Lan, G. Li, Z. Zhao, and G. Jiang, "Distribution of polybrominated diphenyl ethers in the surface sediment of the East China Sea," Chinese Science Bulletin, vol. 59, no. 4, pp. 379387, 2014.

[63] R.-Q. Yang, G.-B. Jiang, Q.-F. Zhou, C.-G. Yuan, and J.-B. Shi, "Occurrence and distribution of organochlorine pesticides (HCH and DDT) in sediments collected from East China Sea," Environment International, vol. 31, no. 6, pp. 799-804, 2005.

[64] C.-C. Hung, G.-C. Gong, K.-T. Jiann et al., "Relationship between carbonaceous materials and polychlorinated biphenyls (PCBs) in the sediments of the Danshui River and adjacent coastal areas, Taiwan," Chemosphere, vol. 65, no. 9, pp. 14521461, 2006.

[65] L. Zeng, Z. Zhao, H. Li et al., "Distribution of short chain chlorinated paraffins in marine sediments of the East China Sea: influencing factors, transport and implications," Environmental Science \& Technology, vol. 46, no. 18, pp. 9898-9906, 2012.

[66] S.-J. Chen, X.-J. Gao, B.-X. Mai et al., "Polybrominated diphenyl ethers in surface sediments of the Yangtze River Delta: levels, distribution and potential hydrodynamic influence," Environmental Pollution, vol. 144, no. 3, pp. 951-957, 2006.

[67] J.-J. Jiang, C.-L. Lee, M.-D. Fang, F.-C. Ko, and J. E. Baker, "Polybrominated diphenyl ethers and polychlorinated biphenyls in sediments of southwest Taiwan: regional characteristics and potential sources," Marine Pollution Bulletin, vol. 62, no. 4, pp. 815-823, 2011.

[68] S. Rayne, M. G. Ikonomou, and B. Antcliffe, "Rapidly increasing polybrominated diphenyl ether concentrations in the Columbia river system from 1992 to 2000," Environmental Science \& Technology, vol. 37, no. 13, pp. 2847-2854, 2003.

[69] B. J. Burd, T. A. Macdonald, R. W. Macdonald, and P. S. Ross, "Distribution and uptake of key polychlorinated biphenyl and polybrominated diphenyl ether congeners in benthic infauna 
relative to sediment organic enrichment," Archives of Environmental Contamination and Toxicology, vol. 67, no. 3, pp. 310-334, 2014.

[70] J. A. Salvadó, J. O. Grimalt, J. F. López, X. Durrieu De Madron, S. Heussner, and M. Canals, "Transformation of PBDE mixtures during sediment transport and resuspension in marine environments (Gulf of Lion, NW Mediterranean Sea)," Environmental Pollution, vol. 168, pp. 87-95, 2012.

[71] H. Zhu, Y. Wang, X. Wang, T. Luan, and N. F. Y. Tam, "Distribution and accumulation of polybrominated diphenyl ethers (PBDEs) in Hong Kong mangrove sediments," Science of the Total Environment, vol. 468-469, pp. 130-139, 2014.

[72] J. P. Boon, W. E. Lewis, M. R. Tjoen-A-Choy et al., "Levels of polybrominated diphenyl ether (PBDE) flame retardants in animals representing different trophic levels of the North Sea food web," Environmental Science and Technology, vol. 36, no. 19, pp. 4025-4032, 2002.

[73] S. Voorspoels, A. Covaci, and P. Schepens, "Polybrominated diphenyl ethers in marine species from the Belgian North Sea and the Western Scheldt Estuary: levels, profiles, and distribution," Environmental Science and Technology, vol. 37, no. 19, pp. 4348-4357, 2003.

[74] K. Vorkamp, J. H. Christensen, and F. Riget, "Polybrominated diphenyl ethers and organochlorine compounds in biota from the marine environment of East Greenland," Science of the Total Environment, vol. 331, no. 1-3, pp. 143-155, 2004.

[75] L. Guo, Y. Qiu, G. Zhang, G. J. Zheng, P. K. S. Lam, and X. $\mathrm{Li}$, "Levels and bioaccumulation of organochlorine pesticides (OCPs) and polybrominated diphenyl ethers (PBDEs) in fishes from the Pearl River estuary and Daya Bay, South China," Environmental Pollution, vol. 152, no. 3, pp. 604-611, 2008.

[76] S. L. Klosterhaus, H. M. Stapleton, M. J. La Guardia, and D. J. Greig, "Brominated and chlorinated flame retardants in San Francisco Bay sediments and wildlife," Environment International, vol. 47, pp. 56-65, 2012.

[77] Y. Zhang, J. Song, Z. He, H. Yuan, and Y. Xu, “Toxic octabromodiphenyl ether is being transported from rich to poor via electronic waste," AMBIO, vol. 38, no. 2, pp. 115-117, 2009.

[78] C. S. Kwan, H. Takada, R. Boonyatumanond et al., "Historical occurrences of polybrominated diphenyl ethers and polychlorinated biphenyls in manila bay, philippines, and in the upper Gulf of Thailand," Science of the Total Environment, vol. 470-471, pp. 427-437, 2014.

[79] C. Marvin, J. Waltho, J. Jia, and D. Burniston, "Spatial distributions and temporal trends in polybrominated diphenyl ethers in Detroit River suspended sediments," Chemosphere, vol. 91, no. 6, pp. 778-783, 2013.

[80] U. S. EPA, An Alternative Assessment for the Flame Retardant Decabromodiphenyl Ether (decaBDE), 2014.

[81] A. F. H. Ter Schure, P. Larsson, C. Agrell, and J. P. Boon, "Atmospheric transport of polybrominated diphenyl ethers and polychlorinated biphenyls to the Baltic Sea," Environmental Science \& Technology, vol. 38, no. 5, pp. 1282-1287, 2004.

[82] Y. Zhao, J. Ma, X. Qiu, Y. Lin, Q. Yang, and T. Zhu, "Gridded field observations of polybrominated diphenyl ethers and decabromodiphenyl ethane in the atmosphere of North China," Environmental Science \& Technology, vol. 47, no. 15, pp. 8123-8129, 2013.

[83] M. Yang, H. Qi, H.-L. Jia et al., "Polybrominated diphenyl ethers in air across China: levels, compositions, and gas-particle partitioning," Environmental Science and Technology, vol. 47, no. 15, pp. 8978-8984, 2013.
[84] I. Watanabe and S.-I. Sakai, "Environmental release and behavior of brominated flame retardants," Environment International, vol. 29, no. 6, pp. 665-682, 2003.

[85] H. M. Stapleton, M. Alaee, R. J. Letcher, and J. E. Baker, “Debromination of the flame retardant decabromodiphenyl ether by juvenile carp (Cyprinus carpio) following dietary exposure," Environmental Science and Technology, vol. 38, no. 1, pp. 112-119, 2004.

[86] K. Booij, B. N. Zegers, and J. P. Boon, "Levels of some polybrominated diphenyl ether (PBDE) flame retardants along the Dutch coast as derived from their accumulation in SPMDs and blue mussels (Mytilus edulis)," Chemosphere, vol. 46, no. 5, pp. 683-688, 2002.

[87] C.-H. Xiang, X.-J. Luo, S.-J. Chen, M. Yu, B.-X. Mai, and E. Y. Zeng, "Polybrominated diphenyl ethers in biota and sediments of the Pearl River Estuary, South China," Environmental Toxicology and Chemistry, vol. 26, no. 4, pp. 616-623, 2007.

[88] R. A. Hites, "Polybrominated diphenyl ethers in the environment and in people: a meta-analysis of concentrations," Environmental Science and Technology, vol. 38, no. 4, pp. 945-956, 2004.

[89] B. Strandberg, N. G. Dodder, I. Basu, and R. A. Hites, "Concentrations and spatial variations of polybrominated diphenyl ethers and other organohalogen compounds in Great Lakes air," Environmental Science and Technology, vol. 35, no. 6, pp. 10781083, 2001.

[90] J. Babayemi, O. Sindiku, O. Osibanjo, and R. Weber, "Substance flow analysis of polybrominated diphenyl ethers in plastic from EEE/WEEE in Nigeria in the frame of Stockholm Convention as a basis for policy advice," Environmental Science and Pollution Research, vol. 22, no. 19, pp. 14502-14514, 2015.

[91] H.-B. Moon, K. Kannan, M. Choi, and H.-G. Choi, "Polybrominated diphenyl ethers (PBDEs) in marine sediments from industrialized bays of Korea," Marine Pollution Bulletin, vol. 54, no. 9, pp. 1402-1412, 2007.

[92] Z. Cheng, T. Lin, W. Xu et al., "A preliminary assessment of polychlorinated biphenyls and polybrominated diphenyl ethers in deep-sea sediments from the Indian Ocean," Marine Pollution Bulletin, vol. 94, no. 1-2, pp. 323-328, 2015.

[93] E. Eljarrat, A. De La Cal, D. Larrazabal et al., "Occurrence of polybrominated diphenylethers, polychlorinated dibenzo-pdioxins, dibenzofurans and biphenyls in coastal sediments from Spain," Environmental Pollution, vol. 136, no. 3, pp. 493-501, 2005.

[94] J. H. Christensen and J. Platz, "Screening of polybrominated diphenyl ethers in blue mussels, marine and freshwater sediments in Denmark," Journal of Environmental Monitoring, vol. 3, no. 5, pp. 543-547, 2001.

[95] H. J. C. Klamer, P. E. G. Leonards, M. H. Lamoree, L. A. Villerius, J. E. Åkerman, and J. F. Bakker, "A chemical and toxicological profile of Dutch North Sea surface sediments," Chemosphere, vol. 58, no. 11, pp. 1579-1587, 2005.

[96] S. Voorspoels, A. Covaci, J. Maervoet, and P. Schepens, "PBDEs in marine and freshwater sediments from Belgium: levels, profiles and relations with biota," Journal of Environmental Monitoring, vol. 6, no. 11, pp. 914-918, 2004.

[97] T. Bakke, S. Boitsov, E. M. Brevik et al., "Mapping selected organic contaminants in the Barents Sea 2007," NIVA-Rapport 5589, 2007. 
[98] E. Barón, P. Gago-Ferrero, M. Gorga et al., "Occurrence of hydrophobic organic pollutants (BFRs and UV-filters) in sediments from South America," Chemosphere, vol. 92, no. 3, pp. 309-316, 2013.

[99] D. Ueno, T. Isobe, K. Ramu et al., "Spatial distribution of hexabromocyclododecanes (HBCDs), polybrominated diphenyl ethers (PBDEs) and organochlorines in bivalves from Japanese coastal waters," Chemosphere, vol. 78, no. 10, pp. 1213-1219, 2010.

[100] Q. Li, C. Yan, Z. Luo, and X. Zhang, "Occurrence and levels of polybrominated diphenyl ethers (PBDEs) in recent sediments and marine organisms from Xiamen offshore areas, China," Marine Pollution Bulletin, vol. 60, no. 3, pp. 464-469, 2010.

[101] B. M. Jenssen, E. G. Sørmo, K. Bæk et al., "Brominated flame retardants in North-East Atlantic marine ecosystems," Environmental Health Perspectives, vol. 115, no. 1, pp. 35-41, 2007. 

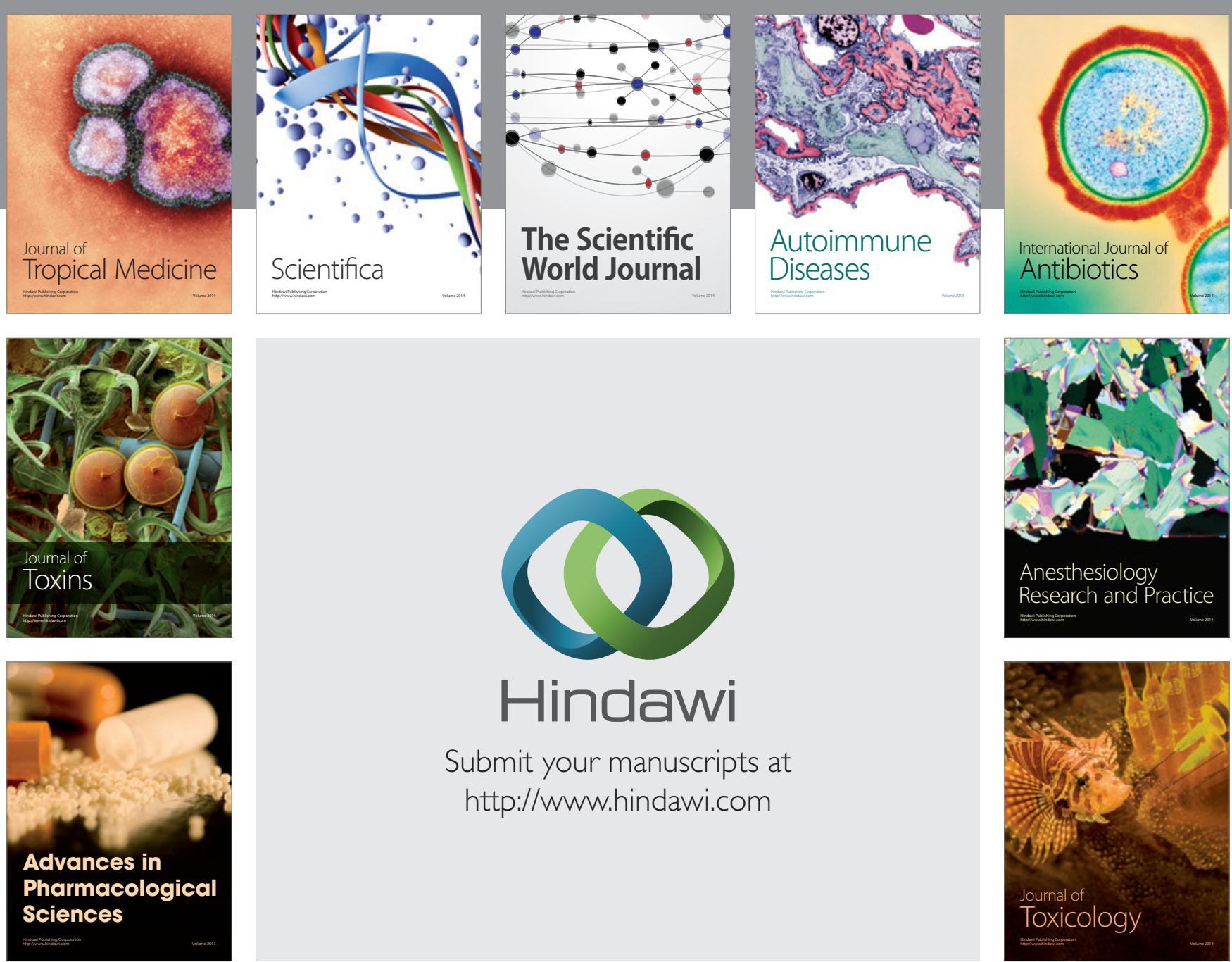

\section{Hindawi}

Submit your manuscripts at

http://www.hindawi.com
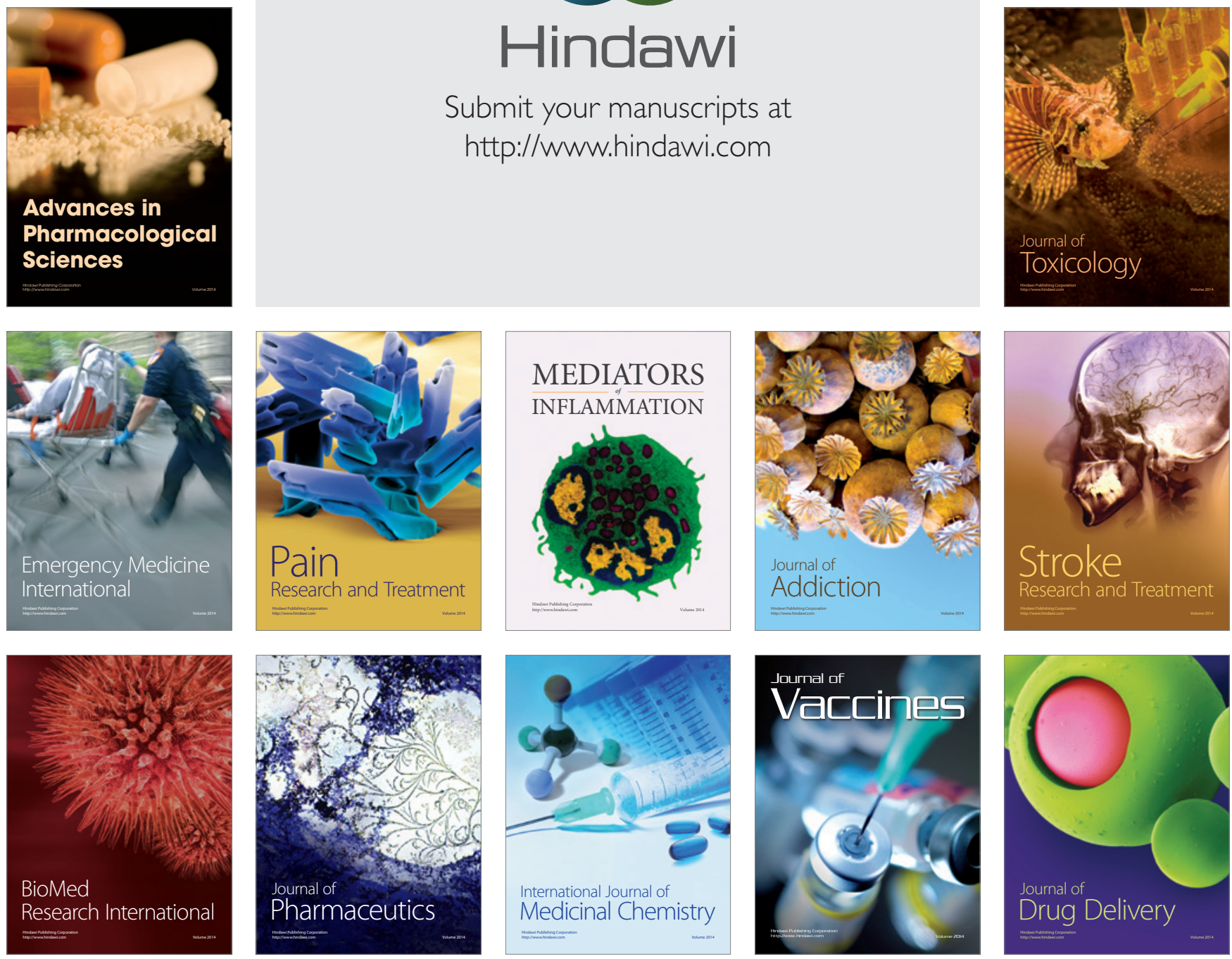